\title{
Altered hypothalamic-pituitary function in the adult female rat with streptozotocin-induced diabetes
}

\author{
M. Spindler-Vomachka ${ }^{1}$ and D.C. Johnson ${ }^{1,2}$ \\ Departments of ${ }^{1}$ Physiology and ${ }^{2}$ Gynecology and Obstetrics, Ralph L. Smith Research Center, University of Kansas Medical Center, \\ Kansas City, Kansas, USA
}

\begin{abstract}
Summary. Infertility associated with anovulation and loss of regular oestrous cyclicity is a consequence of diabetes mellitus in the rat. In an attempt to define loci of altered function, studies were undertaken to examine various aspects of hypothalamic-pituitary function in rats treated with streptozotocin. Medial basal hypothalamic fragments from adult female diabetic rats contained the same amount of gonadotrophin-releasing hormone but, with depolarization, released slightly but insignificantly $(p>0.05)$ more than did those from control animals. Furthermore, release of luteinizing hormone from pituitaries exposed to hypothalamic gonadotrophin-releasing hormone was not altered by diabetes. Removal of the negative feedback effect of gonadal steroids upon the hypothalamicpituitary axis produced an increase in luteinizing hormone and follicle stimulating hormone concentrations in the serum of normal rats within $6 \mathrm{~h}(p<0.05)$, whereas $24 \mathrm{~h}$ were required for similar increases in diabetic rats. However, the same concentrations of gonadotrophins were found in diabetic and control animals $120 \mathrm{~h}$ after ovariectomy. The inhibitory action of oestradiol benzoate on the secretion of gonadotrophins was more pronounced in ovariectomized diabetic than in control rats. A 74\% depression in serum luteinizing hormone $(p<0.01)$ was produced by $0.5 \mu \mathrm{g}$ oestradiol benzoate per day in diabetic rats, while $5 \mu \mathrm{g}$ was required in control ani-
\end{abstract}

mals. Similar reductions in follicle stimulating hormone concentrations $(50 \%, p<0.05)$ were obtained by injecting $5 \mu \mathrm{g}$ of the oestrogen into diabetic or $50 \mu \mathrm{g}$ into control rats. Increases in serum prolactin were greater in the control animals however. Although pituitary weights were consistently lower in oestrogen-treated diabetic than in control animals, the luteinizing hormone, follicle stimulating hormone and prolactin contents, on the basis of wet weight of gland, were not different $(p>0.05)$. The positive feedback action of progesterone on release of luteinizing hormone that had been suppressed with oestradiol benzoate was delayed by $3 \mathrm{~h}$ and reduced by more than $50 \%$ in diabetic compared to control animals $(p<0.01)$. Release of follicle stimulating hormone was also delayed and reduced in the diabetic rats. While several indices of hypothalamic-pituitary function were not greatly altered by streptozotocin-induced diabetes, the enhanced negative and reduced positive-feedback effects of steroids could be responsible for attenuated gonadotrophin surges and loss of cyclicity in diabetic female rats.

Key words: Diabetic rat, gonadotrophins, hypothalamic fragments, gonadotrophin-releasing hormone, oestradiol, feedback, negative and positive.
Reproductive failure in the female rat with experimentally induced diabetes mellitus is well known [1-3]. In spite of extensive investigation, controversy has developed over which site is the prime contributor to the poor reproductive performance. Some investigators have proposed a defect in hypothalamic-pituitary function $[1,2]$, while others have favoured reduced ovarian sensitivity to hormones $[4,5]$. As yet, there has been no resolution of this debate. Early studies indicated that a deficiency in either the synthesis or release of pituitary gonadotrophins was responsible for reduced ovarian size and lack of oestrous cyclicity in the diabetic rat [2]. Actual measurements of gonadotrophin concentrations in the diabetic female, however, have been limited and have given conflicting results [3-6]. Loss of ovulation in immature female rats made diabetic with alloxan has been associated with a reduction in, or a lack of, release of hypothalamic gonadotrophin-releasing hormone (GnRH) [3]. Other reports have indicated that the cause of ovulatory failure is the result of the diabetic female's inability to respond to GnRH [7].

In the present study, attention has focussed upon hypothalamic-pituitary functions in the adult acutely diabetic female rat. Ovariectomy was presumed to be an adequate test for the capacity of the hypothalamic-pituitary axis to respond to a loss of ovarian negative feedback effects. In addition, the negative and positive feedback effects of steroids upon the axis were tested. 


\section{Materials and methods}

\section{Animals}

Two hundred and twenty female rats of the Holtzman strain (Holtzman, Madison, Wisconsin), weighing $150-200 \mathrm{~g}$, were maintained in temperature $\left(25 \pm 2^{\circ} \mathrm{C}\right)$ and light-controlled quarters $(12 \mathrm{~h} \mathrm{light/day)}$ with free access to Purina laboratory chow and tap water. Diabetes mellitus was induced with streptozotocin $(50$ or $75 \mathrm{mg} / \mathrm{kg}$ body weight, intravenously). The compound (Sigma Chemicals, St. Louis, Missouri) was dissolved in $0.01 \mathrm{~mol} / 1$ citrate buffer ( $\mathrm{pH} \mathrm{4.5)} \mathrm{just} \mathrm{be-}$ fore use. Control animals were given the citrate buffer solution only. Indication of diabetes was obtained from serum and urine glucose determinations using the glucose oxidase assay [8] for the former and Uristix (Ames, Elkhart, Indiana) for the latter. Urinary glucose was demonstrable within $48 \mathrm{~h}$ after injection of streptozotocin.

\section{Experiment 1: Changes in gonadotrophin release after removal of gonadal steroids}

The acute changes in the concentration of gonadotrophins in the serum were studied following ovariectomy in animals with established diabetes. Eight days after treatment with strepozotocin $(50 \mathrm{mg} / \mathrm{kg})$, 30 diabetic and 30 non-diabetic rats were bilaterally ovariectomized via a dorsolateral incision, using deep ether anaesthesia. Vaginal smears, taken over a period of two oestrous cycles, indicated that the diabetic animals were in dioestrus; all control animals were also in dioestrus at the time of ovariectomy. The animals were subdivided into six groups of five rats each. Blood samples $(1 \mathrm{ml})$ were obtained via the ventral tail artery, under light ether anaesthesia, at $0,6,12,18,24$, $36,48,60,72,96$ and $120 \mathrm{~h}$ after ovariectomy. Animals were not bled more than twice, and not more than once per $24 \mathrm{~h}$.

\section{Experiment 2: Inhibition of gonadotrophin release by exogenous oestradiol}

Sixty rats were bilaterally ovariectomized, using deep ether anaesthesia, without regard to their stage in the oestrous cycle. Two weeks later half of the animals were injected with strepozotocin $(75 \mathrm{mg} / \mathrm{kg})$. Three days after this treatment the diabetic and control animals were randomly assigned to one of five treatment groups. Each animal received a subcutaneous injection of oestradiol benzoate (OEB) once daily for 7 days; the doses were $0.05,0.5,5$, or $50 \mu$ dissolved in $0.1 \mathrm{ml}$ of sesame seed oil; controls received oil only. Animals were killed $24 \mathrm{~h}$ after the last injection. The entire pituitary gland was removed, weighed, and stored frozen in $1 \mathrm{ml}$ of $0.1 \mathrm{~mol} / 1$ phosphate buffered saline ( $\mathrm{pH}$ 7.4). Prior to assay the pituitaries were sonicated ( 540 watts/in a micro-ultrasonic cell distrupter, Kontes, Evanston, Illinois) and centrifuged at $2200 \mathrm{~g}$ for $15 \mathrm{~min}$. The supernatant fluid was further diluted with phosphate buffered saline, containing $1 \%$ egg albumin, to a concentration of $1 \mathrm{mg} / \mathrm{ml}$.

\section{Experiment 3: Effect of progesterone upon release of gonadotrophin in ovariectomized females treated with oestradiol benzoate}

The positive feedback response of the pituitary was studied in longterm ovariectomized animals. One month after ovariectomy 35 rats were injected with either streptozotocin $(75 \mathrm{mg} / \mathrm{kg})$ or $0.1 \mathrm{~mol} / 1 \mathrm{ci}-$ trate buffer. One week later they were injected subcutaneously once daily for 2 days with $25 \mu \mathrm{g}$ of OEB. On the third day each animal received subcutaneously $5 \mathrm{mg}$ of progesterone dissolved in $0.2 \mathrm{ml}$ of sesame seed oil. Blood samples were obtained from at least five rats at the time of the latter injection and at 3-h intervals over the next $12 \mathrm{~h}$ : no animal was bled more than twice. A 24-h blood sample was obtained by decapitation.

The blood samples were allowed to clot at room temperature for $15 \mathrm{~min}$ followed by centrifugation at $2200 \mathrm{~g}$ at $4^{\circ} \mathrm{C}$ for $30 \mathrm{~min}$. The serum was separated and stored at $-20^{\circ} \mathrm{C}$ until assayed.

\section{Experiment 4: The response of the anterior pituitary to GnRH in vitro and the release of GnRH from hypothalamic tissue in vitro}

Twenty rats were injected intravenously with either streptozotocin $(75 \mathrm{mg} / \mathrm{kg}$ ) or $0.1 \mathrm{~mol} / \mathrm{l}$ citrate buffer. Five days later they were decapitated and their tissues prepared for incubation. Details of the procedure have been published elsewhere [9]. In brief, this consists of rapid removal of the medial basal hypothalamus and pituitary. The boundaries of the medial basal hypothalamic fragments used were defined rostrally by the optic chiasm and caudally by the mammillary bodies; they were $2 \mathrm{~mm}$ wide and $1 \mathrm{~mm}$ thick $(7-10 \mathrm{mg}$ wet weight). Following removal of the posterior pituitary in situ, the anterior pituitary was gently detached and bisected along the midline. Both halves of the pituitary and the hypothalamic fragments were pooled in separate vials containing $4 \mathrm{ml}$ of incubation media. Krebs-Ringer bicarbonate buffer (pH 7.4), containing glucose $(11.1 \mathrm{mmol} / \mathrm{l})$ bovine serum albumin (41.6 mmol $/ 1$, radioimmunoassay grade, Sigma), bacitracin $(1 \mathrm{mmol} /$ 1) and dithiothretiol $(20 \mu \mathrm{mol} / \mathrm{l})$, was used as the incubation medium. The medium was gassed with $95 \% \mathrm{O}_{2}+5 \% \mathrm{CO}_{2}$. All incubations were performed in stoppered glass vials under an atmosphere of $95 \%$ $\mathrm{O}_{2}+5 \% \mathrm{CO}_{2}$ in a Dubnoff metabolic shaking incubator (65 shakes/ $\mathrm{min}$ ) at $37^{\circ} \mathrm{C}$. Two $30 \mathrm{~min}$ pre-incubations, each with fresh medium, of pooled hypothalamic fragments and pooled pituitary halves preceded the test incubation. Individual hypothalamic fragments or hemipituitaries were transferred to separate vials containing $1 \mathrm{ml}$ of fresh medium with test substance or vehicle. The release of GnRH from hypothalamic fragments was tested with veratrine (Sigma). This compound, which is a mixture of four veratrum alkaloids, depolarizes nervous tissue by activating sodium channels involved in action potential generation [10]. The veratrine was initially dissolved in $\mathrm{HCl}$ $(0.1 \mathrm{~mol} / 1)$, and serially diluted with $\mathrm{HCl}(5 \mathrm{mmol} / \mathrm{l})$ in saline $(0.154 \mathrm{mmol} / \mathrm{l})$ containing $1 \%$ bovine serum albumin, to a final concentration of $0.134 \mathrm{mg} / \mathrm{ml}$. A concentration of $6.7 \mathrm{mg} / 1$ of veratrine was used in the incubation. The effect of GnRH on pituitary tissue was examined using $0,50,500$ and $5000 \mathrm{ng} / \mathrm{l}$ of the neuropeptide. At the termination of the incubation the medium was removed with a pipette and stored at $-20^{\circ} \mathrm{C}$ until assayed. The tissue fragments were removed, weighed, sonicated in a volume equal to their weight and stored at $-20^{\circ} \mathrm{C}$ until assayed.

\section{Assays}

The luteinizing hormone (LH), follicle stimulating hormone (FSH) and prolactin contents of the sera, incubation media or pituitary homogenates were measured by double-antibody radioimmunoassays. The procedures employed have been published in detail elsewhere [11]. Antibodies and reference preparations were provided as kits by the National Institute of Arthritis, Diabetes, and Digestive and Kidney Diseases, National Institutes of Health, Bethesda, Maryland. Hormone concentrations were expressed in $\mathrm{ng} / \mathrm{ml}$ of serum on the basis of standard reference preparations (RP-1) supplied with each kit. Homogenates of pituitary fragments were assayed at two dose levels and the concentration of hormones expressed at $\mu \mathrm{g} / \mathrm{mg}$. All samples from a particular study were included in the same assay; intraassay coefficients of variation did not exceed $10 \%$.

The radioimmunoassay of GnRH used a modification [9] of the methods outlined by Nett and Adams [12]. Anti-GnRH (r-42) was kindly provided by Dr. G.D. Niswender, Colorado State University, Fort Collins, Colorado. Standards or samples were added to the antiserum and labelled antigen at the same time and incubated for $24 \mathrm{~h}$. Separation of bound from free ${ }^{125} \mathrm{I}-\mathrm{GnRH}$ was accomplished by addition of two volumes of $95 \%$ ethanol and centrifugation at $2200 \mathrm{~g}$ for $30 \mathrm{~min}$.

Oestradiol was assayed by radioimmunoassay using the method described previously [13]. Tritiated oestradiol $\left(2,4,6,7{ }^{3} \mathrm{H}(\mathrm{N})\right.$-estradiol $17 \beta ; 115 \mathrm{Ci} / \mathrm{mmol}$ ) was obtained from New England Nuclear, Boston, Massachusetts and used without further purification. The antioestradiol antibody, was prepared, characterized and provided by Exley et al. [14]. Serum from ovariectomized and adrenalectomized adult 

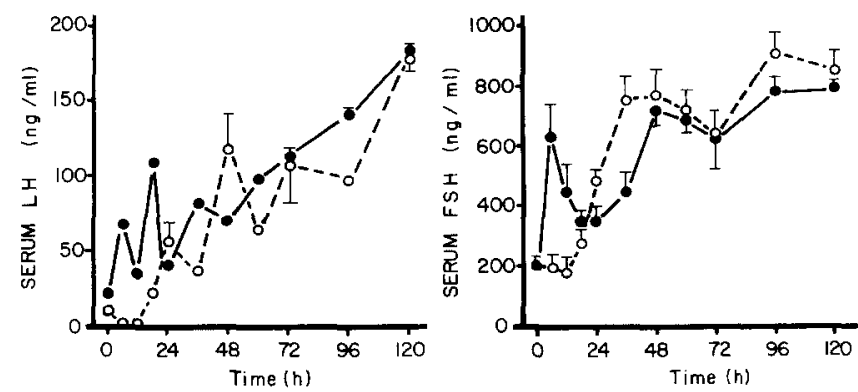

Fig. 1. Changes in the concentrations of LH and FSH in the sera of normal $(-0)$ and diabetic $(\mathrm{O}----\mathrm{O})$ rats following ovariectomy at time 0 . Adult animals were injected intravenously with streptozotocin $(50 \mathrm{mg} / \mathrm{kg}$ body weight) or citrate buffer ( $\mathrm{pH} 4.5$ ) and ovariectomized 8 days later: both groups were in dioestrus at the time of ovariectomy. The LH values at 6,12 , and $18 \mathrm{~h}$ and the FSH values at 6 and $12 \mathrm{~h}$ were significantly lower in the diabetic than in the control animals $(p<0.05)$. Within $120 \mathrm{~h}$ the concentrations were the same in both groups of rats. Vertical lines indicate SEM for groups of five rats

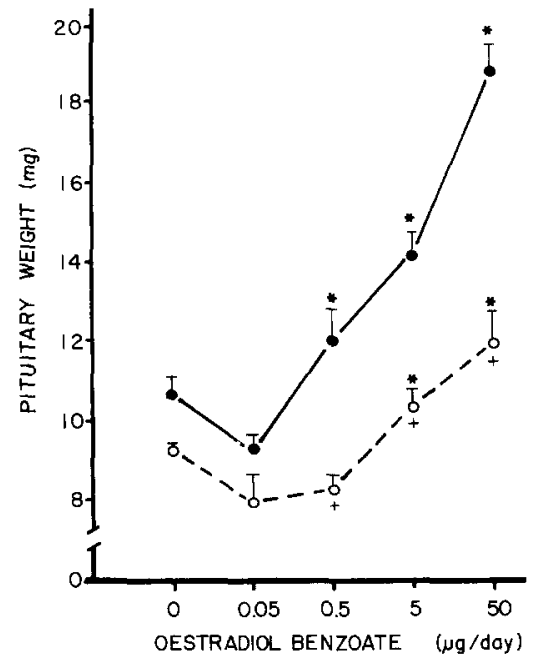

Fig. 2. Effects of seven daily subcutaneous injections of various doses of oestradiol benzoate or oil upon pituitary weight of normal (-) or diabetic (O-----O) ovariectomized rats. Streptozotocin $(75 \mathrm{mg} / \mathrm{kg}$ body weight) was given intravenously 3 days before starting the treatment; the ovaries had been removed 14 days earlier. Vertical lines indicate SEM for groups of six rats: $* ; p<0.05$ significant differences from oil-injected control rats; $+p<0.01$ significant differences between control and diabetic animals female rats was added to each standard and extracted in the same fashion as the unknowns. Results are expressed as amount of oestra$\mathrm{diol} / \mathrm{ml}$ of serum.

\section{Statistical analysis}

Data were analyzed using a one-way or a two-way analysis of variance. Multiple comparisons were made using Tukey's test. When appropriate, an independent Student's t-test was applied. A $p$ value $<0.05$ was considered statistically significant.

\section{Results}

There are different degrees of insulin deprivation following experimental induction of diabetes mellitus. Within 2-3 days use of $50 \mathrm{mg} / \mathrm{kg}$ of streptozotocin produced a non-fasting concentration of serum glucose of $16.6 \pm 1.3 \mathrm{mmol} / 1$ compared with control values of $5.1 \pm 0.66 \mathrm{mmol} / 1$. The $75 \mathrm{mg} / \mathrm{kg}$ dose, which was used in all but one experiment, produced a slightly higher concentration of glucose (range $17.2-25.0 \mathrm{mmol} / 1$; mean value $19.7 \pm 0.6 \mathrm{mmol} / \mathrm{l})$. While the animals used may not have been totally lacking in insulin, all were distinctly hyperglycaemic.

The acute changes in the circulating levels of FSH and $\mathrm{LH}$ following ovariectomy of normal or diabetic female rats are shown in Figure 1. The prompt increase in serum concentrations of both hormones seen in the controls is missing in the diabetic animals. However, within $24 \mathrm{~h}$ increased concentrations were evident in the diabetic rats and within $120 \mathrm{~h}$ the concentrations of both gonadotrophins were indistinguishable from those of the controls.

Examination of pituitary weights after 7 days of oestrogen treatment revealed a change in the oestrogen dose response curve in the diabetic castrated females (Fig. 2). Pituitary weight decreased slightly, but not significantly, in both control and diabetic ovariectomized animals given $0.05 \mu \mathrm{g} \mathrm{OEB} /$ day. While a significant increase in pituitary weight was obtained with $0.5 \mu \mathrm{g}$ $\mathrm{OEB} /$ day in controls $(p<0.05)$, a dose of $5 \mu \mathrm{g}$ was nec-
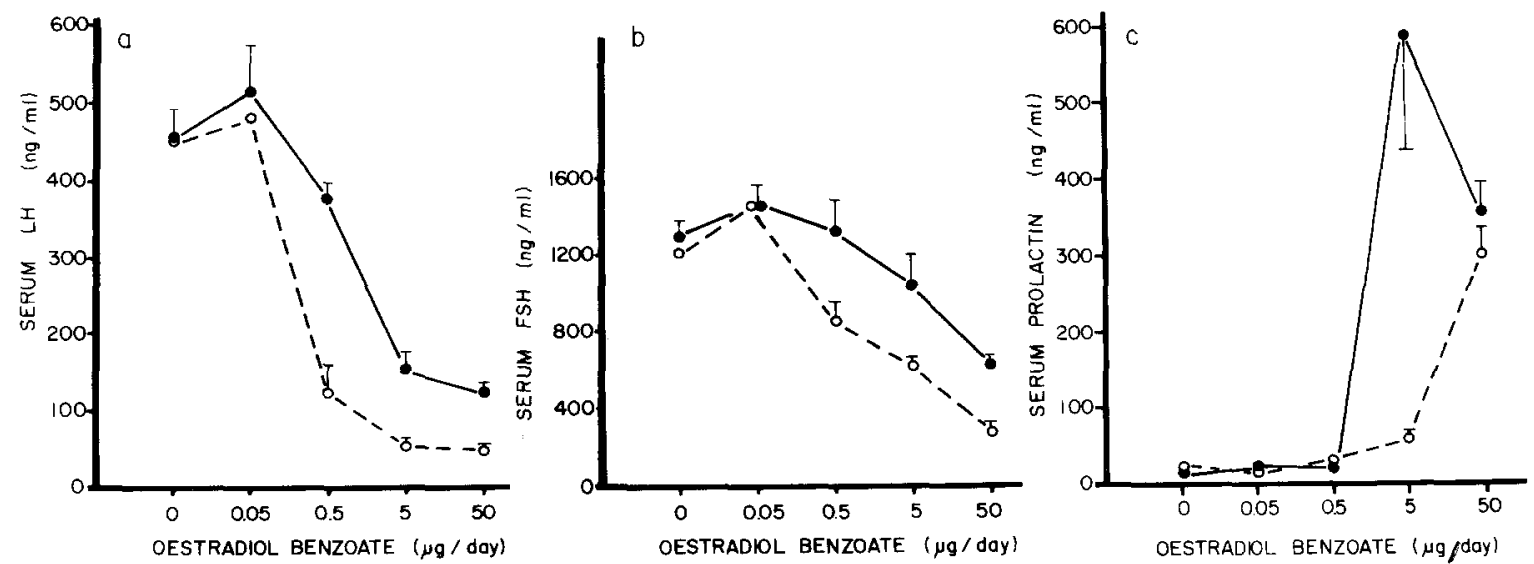

Fig. 3. Changes in the concentrations of serum LH (a), FSH (b) and prolactin (c) in normal (-- - or diabetic (O---O) ovariectomized rats treated with various doses of oestradiol benzoate: details are given in the legend of Figure 2 . The diabetic animals had a significantly greater reduction in LH and FSH with the largest three doses of oestrogen than did the control animals $(p<0.01)$ 

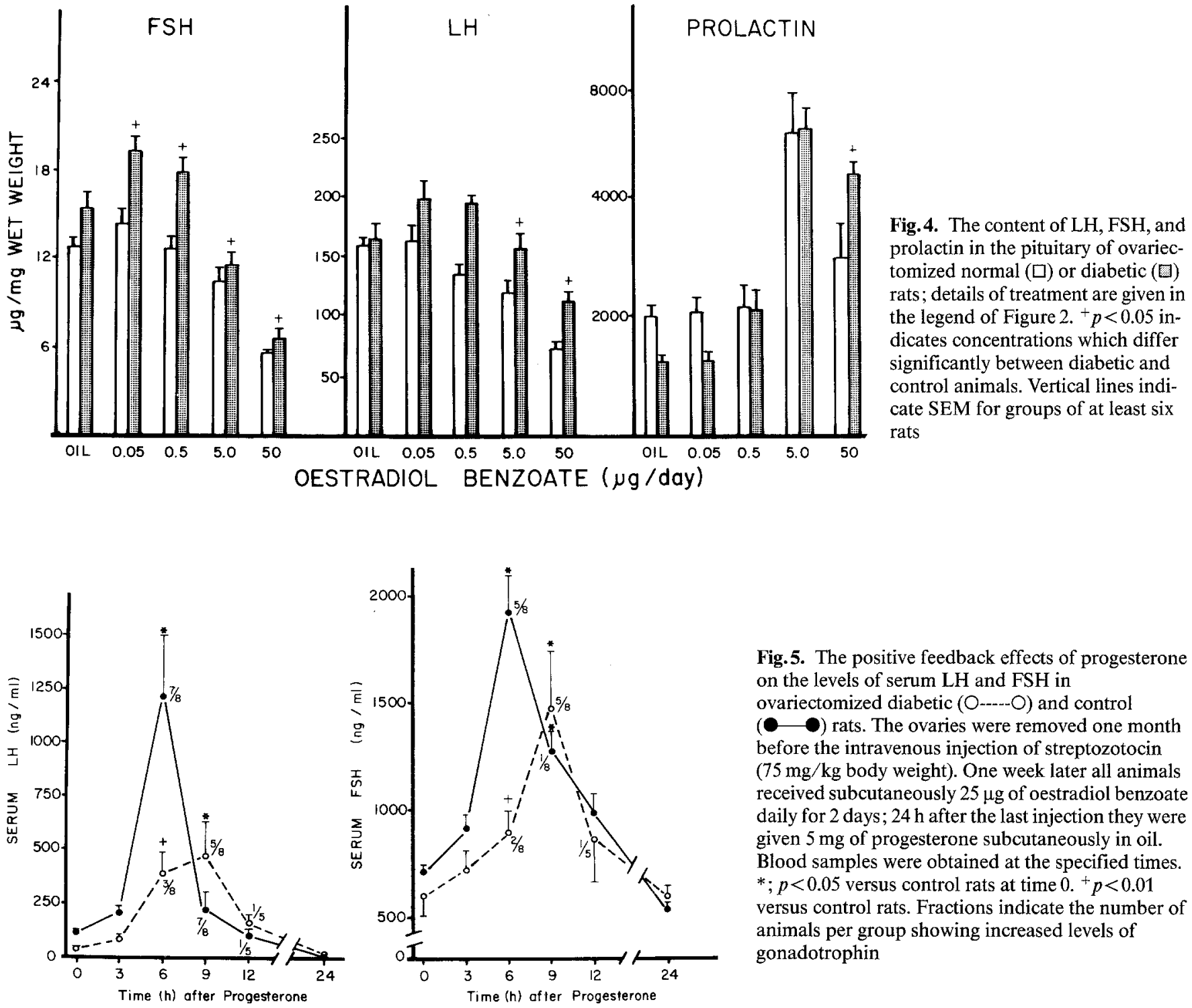

Fig.5. The positive feedback effects of progesterone on the levels of serum LH and FSH in

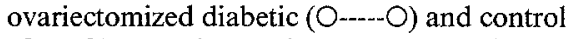
(-) rats. The ovaries were removed one month before the intravenous injection of streptozotocin ( $75 \mathrm{mg} / \mathrm{kg}$ body weight). One week later all animals received subcutaneously $25 \mu \mathrm{g}$ of oestradiol benzoate daily for 2 days; $24 \mathrm{~h}$ after the last injection they were given $5 \mathrm{mg}$ of progesterone subcutaneously in oil. Blood samples were obtained at the specified times. ${ }^{*} ; p<0.05$ versus control rats at time $0 .{ }^{+} p<0.01$ versus control rats. Fractions indicate the number of animals per group showing increased levels of gonadotrophin

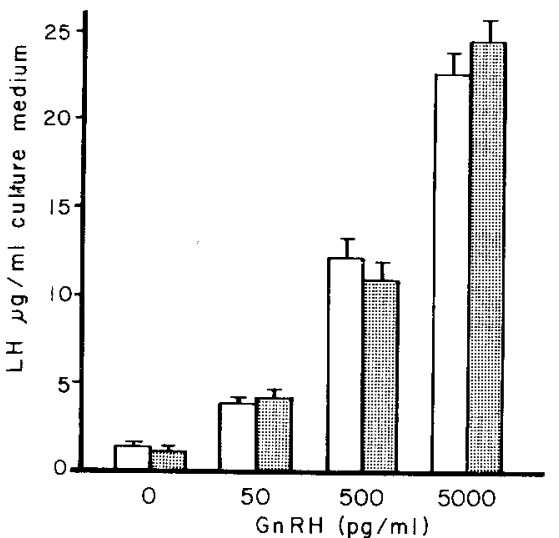

Fig. 6. The amount of $\mathrm{LH}$ released into the media by hemi-pituitaries from diabetic (알) or control $(\square)$ animals which were incubated with synthetic GnRH. Incubation was for $3 \mathrm{~h}$ in Krebs-Ringer bicarbonate buffer. The SEM is indicated above the bars which represent the mean for each incubation of four or five hemi-pituitaries. With all doses of $\mathrm{GnRH}$ the amount of $\mathrm{LH}$ released was significantly greater than from control tissues $(p<0.01)$, but in no case was the amount released greater in tissue from diabetic than control animals $(p>0.05)$ essary to obtain a change in the diabetic animals $(p<$ 0.05 ). Even with $50 \mu \mathrm{g} \mathrm{OEB} /$ day, pituitary weight in the diabetic animals was not different from that produced by $0.5 \mu \mathrm{g} /$ day in the control rats.

The oestrogen dose-response curve for inhibition of LH and FSH secretion was shifted to the left in diabetic ovariectomized rats (Fig. 3). The concentrations of LH in the sera of ovariectomized diabetic and control rats given oil did not differ. With the administration of $0.5 \mu \mathrm{g} \mathrm{OEB} /$ day, the level of LH decreased $>70 \%$ in the diabetic rats compared with $17 \%$ decrease in the control animals. The maximum decrease in LH was achieved with $5 \mu \mathrm{g} \mathrm{OEB/day} \mathrm{in} \mathrm{both} \mathrm{control} \mathrm{and} \mathrm{dia-}$ betic animals. However, the minimum concentration of LH in the diabetic animal was only about half that of the non-diabetic animal. The effects of OEB on the concentrations of FSH were similar to those observed on LH (Fig. 3b). After a slight, non-significant increase with a small dose of OEB, the concentration declined more in diabetic rats given $0.5 \mu \mathrm{g} \mathrm{OEB} / \mathrm{day}$ than in con- 
trol animals. A dose of $5 \mu \mathrm{g} \mathrm{OEB} /$ day was required to produce a significant decrease in FSH in the control animals $(p<0.05)$; a further decrease was obtained by a tenfold increase in the dose of OEB. As with LH, the concentration of FSH in the sera of diabetic animals given the larger doses of OEB was about half that of normal animals given the same amount of hormone.

The effect of oestrogen on prolactin secretion was opposite to that on the gonadotrophins. In diabetic rats, it took ten times more OEB to produce a rise in prolactin that was comparable to the increase obtained in nondiabetic animals. The levels of prolactin did not change in control or diabetic animals given 0.05 or $0.5 \mu \mathrm{g} \mathrm{OEB} /$ day (Fig. 3 c). However, a profound and maximal increase was obtained in non-diabetic ovariectomized females injected with $5 \mu \mathrm{g} /$ day; the larger dose caused a decrease. In contrast, the concentration of prolactin in diabetic animals did not increase markedly unless they received $50 \mu \mathrm{g} /$ day.

Expressed per gland, the pituitary gonadotrophin content of the diabetic was considerably less than that of the control animals. However, when expressed as $\mu \mathrm{g}$ of hormone/mg of pituitary tissue, the values for diabetic were the same or higher than those for control animals (Fig.4). Small doses of OEB increased the pituitary concentration of FSH in the diabetic $(p<0.05)$, but not the control animals. The pattern of change in LH was similar. With larger doses of OEB the pituitary concentration decreased; in all cases the diabetic had a higher concentration than did the control animals. The concentration of prolactin did not differ between diabetic and control rats except in those given $50 \mu \mathrm{g} \mathrm{OEB} /$ day (Fig.4). At this dose of oestrogen the concentration of prolactin was higher in diabetic than in control rats $(p<0.02)$.

The characteristics of the positive feedback effects of oestrogen and progesterone on gonadotrophin secretion in diabetic ovariectomized rats are shown in Figure 5 . When ovariectomized oestrogen-primed rats were injected with a single dose of progesterone, the concentration of $\mathrm{LH}$ in the serum increased only slightly within the first $3 \mathrm{~h}$, but dramatically increased within $6 \mathrm{~h}$. Within another $3 \mathrm{~h}$ the level had fallen to the starting level. In diabetic animals the same treatment produced a much smaller rise in LH and only three out of eight animals had increased levels at $6 \mathrm{~h}$. At $9 \mathrm{~h}$ after the progesterone, five out of eight diabetic animals had increased levels of $\mathrm{LH}$, but the concentration was less than half that found in control rats at $6 \mathrm{~h}$. This reduction in diabetic animals, despite an increase in $\mathrm{LH}$, was 15 times greater than baseline levels.

The pattern of changes in FSH concentrations was similar to those of LH (Fig. 5 b). FSH in the serum nearly tripled in five out of eight control animals within $6 \mathrm{~h}$ of receiving the progesterone. The slower rate of decrease, compared with that of $\mathrm{LH}$, reflects the longer half-life of this hormone in serum. In the diabetic rats five out of eight had increased FSH levels, also almost triple the starting level, but not until $9 \mathrm{~h}$ after progesterone; the concentration fell quickly in these animals.

The GnRH content of the hypothalamic fragments was not different in diabetic and control animals; the mean value for the tissue from both groups of animals was $3150 \pm 340 \mathrm{pg} /$ fragment. Hypothalamic fragments from diabetic animals released the same amount of $\mathrm{GnRH}$ into the incubation medium during a 3-h incu-

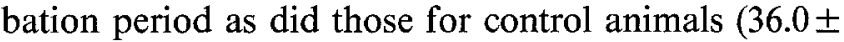
$4.8 \mathrm{pg} / \mathrm{fragment}$ for the diabetic and $28.0 \pm$ $5.6 \mathrm{pg} /$ fragment for control tissues). When the depolarizing agent, veratrine, was included in the medium, the hypothalamic fragments from the diabetic animal released slightly more GnRH than did those from control animals (784 \pm 108 versus $496 \pm 64 \mathrm{pg} /$ fragment, $p>$ 0.05).

The response of anterior pituitary tissue to $\mathrm{GnRH}$ in vitro is shown in Figure 6. Significant increases in LH, released into the medium during a 3-h incubation period, were obtained with $50 \mathrm{pg} / \mathrm{ml}$ of $\mathrm{GnRH}(p<0.01)$. Larger doses produced proportionately larger amounts of LH from pituitary halves from both diabetic and control animals. There were no significant differences between the two groups of animals with regard to the amount of LH released.

\section{Discussion}

The hypothalamic-pituitary gonadotrophin-releasing mechanisms are functional in the adult diabetic female rat. In confirmation of other studies [7] the hypothalamic content of GnRH did not differ and the release of this neuropeptide in response to veratrine was as good in tissue from diabetic as that from normal animals. Furthermore, the response of the pituitary to $\mathrm{GnRH}$ in vitro also appears unaffected by the diabetic syndrome; essentially identical responses in LH release were obtained from pituitaries of diabetic and control animals (Fig. 6).

Our preliminary studies (data not shown) had indicated that induction of diabetes with streptozotocin after ovariectomy did not alter the concentrations of FSH or LH in the serum. When ovariectomy was carried out after the establishment of diabetes, only slight changes in gonadotrophic responses were found. In agreement with several previous studies [15-17], ovariectomy of normal females in dioestrus resulted in a prompt, but transient, increase in FSH and LH in the serum. This initial rise in hormone output was missing in the diabetic animals. However, within $48 \mathrm{~h}$ the concentrations of FSH and LH in the diabetic and control animals were similar. The lack of an initial response may be due to quantitative and/or temporal changes in adrenal function between normal and diabetic animals which could alter the response to gonad removal [15]. These different methods thus demonstrate that the hypothalamic-hypophyseal axis of the diabetic rat functions 
adequately when judged on the basis of synthesis and release of gonadotrophins and the response to GnRH.

The negative feedback effects of OEB indicated that the hypothalamic-pituitary axis of the diabetic was more sensitive than that of control animals. However, while the output of LH and FSH decreased further in diabetic than normal animals treated with small doses of OEB, prolactin secretion was distinctly less in diabetic animals. Even with the highest dose of OEB the prolactin concentration in diabetic animals was considerably lower than in the controls. The consequences of this altered prolactin response are unknown, but they may explain the retention of corpora lutea in diabetic animals [4].

The effects of oestrogen on the synthesis of gonadotrophins in the diabetic rat are more difficult to assess. Although the pituitary weight increase found in normal animals was attenuated in the diabetic rats (Fig. 2), the amount of LH, FSH and prolactin contained in the gland, when expressed as $\mu \mathrm{g} / \mathrm{mg}$ wet weight of pituitary, was equal to, or greater than, those of control rats. A previous study [7] also noted that the pituitary content of LH in diabetic animals was elevated under gonadal stimulation. Coupled with reduced concentrations of $\mathrm{LH}, \mathrm{FSH}$ and prolactin in the serum increased pituitary content suggested that the diabetes enhanced the responsiveness to oestrogen resulting in deficient gonadotrophin release. This notion is further strengthened by the finding that no differences in the clearance of oestrogen between the two kinds of animals can be demonstrated (unpublished data).

Perhaps the most important gonadotrophic differences associated with diabetes were found with the positive feedback study. While increases in LH and FSH were produced, the time of onset of the surges was delayed in diabetic animals compared to that of controls and the amount of the increase was reduced. Variability in the time of occurrence was also greater in diabetic animals. These results suggest that the hypothalamic-hypophyseal defect in the diabetic female rat may not be with the synthesis of GnRH or gonadotrophins, or in the response of the pituitary to $\mathrm{GnRH}$, but rather involves the various steps of oestrogen and progesterone priming that leads to increased secretion of GnRH and therefore release of $\mathrm{LH}$ and FSH.

The mechanism for the alteration in the feedback dynamics in the diabetic female rat remains unknown. Glucocorticoids, which are elevated in the serum of the diabetic rat [18, 19], have been shown to be anti-oestrogenic and to interfere with the priming action of oestrogen. The administration of adrenal steroids $2-8 \mathrm{~h}$ after the injection of OEB was found to suppress the induced increase in concentration of $\mathrm{LH}$ in the sera of ovariectomized rats [20]. The secretion of FSH was unaffected by this treatment. Another possible consequence of insulin deficiency, and its metabolic sequel, is the reported decrease in the uptake of oestradiol by the hypothalamic-pre-optic area and the pituitary gland [21]. This reduction has been correlated with interruption in the priming action of gonadal steroids for the induction of lordosis behaviour [22]. Since the genomic action of oestrogen has been postulated as essential for conditioning of the central nervous system [23], the decreased uptake and binding of oestradiol in the hypothalamus and pituitary on the part of the diabetic rat would create the potential for altered feedback effects of oestrogen and progesterone on release of $\mathrm{LH}, \mathrm{FSH}$ and prolactin.

In summary, the results of this study are consistent with the view that the enhanced negative feedback effect of oestrogen upon the hypothalamic-pituitary axis, coupled with the reduced positive feedback action of progesterone, may be responsible for the attenuated surge of gonadotrophins and loss of cyclicity exhibited by the adult diabetic female rat.

Acknowledgments. We thank the National Institute of Arthritis, Diabetes and Digestive and Kidney Diseases for supplying the radioimmunoassay kits and Dr. G.D. Niswender for supplying the antiGnRH antibody. Thanks are also due Dr. C.A.Powers and Mrs. M. A. Wagoner for excellent technical assistance.

\section{References}

1. Shipley EG, Danley KS (1947) Pituitary and ovarian dysfunction in experimental diabetes. Am J Physiol 150:84-88

2. Chieri RA, Pivetta OH, Foglia (1969) Altered ovulation patterns in experimental diabetes. Fert Steril 20:661-666

3. Kirchick HJ, Keyes PL, Frye BE (1978) Etiology of anovulation in the immature alloxan diabetic rat treated with pregnant mare's serum gonadotropin: absence of the preovulatory LH surge. Endocrinology 102: 1867-1873

4. Lawrence AM, Contopoulos AN, Simpson ME (1958) Pituitary and plasma bioassay of tropic hormones in alloxan diabetic rat. Proc Soc Exper Biol Med 99: 35-38

5. Liu FTY, Lin HS, Johnson DC (1972) Serum FSH, LH and the ovarian response to exogenous gonadotrophins in alloxan diabetic immature female rats. Endocrinology 91: 1172-1179

6. Howland BE, Zebrowski EJ (1974) Gonadotrophin levels in sera and pituitary glands of female rats treated with alloxan. Life Sci 14: $289-292$

7. Kirchick HJ, Keyes PL, Frye BE (1979) An explanation for anovulation in immature alloxan-diabetic rats treated with pregnant mare's serum gonadotrophin: reduced pituitary response to gonadotrophin-releasing hormone. Endocrinology 105: 1343-1349

8. Marks V (1959) An improved glucose oxidase method for determining blood, CSF and urine glucose levels. Clin Chim Acta 4: 395-401

9. Powers CA, Johnson DC (1980) Release of gonadotrophin releasing hormone by veratrine in a hypothalamic-pituitary incubation. Eur J Pharm 66: 161-167

10. Vermes I, Mulder GH, Smelik PG (1977) A superfusion system technique for the study of the sites of action of glucocorticoids in the rat hypothalamus-pituitary cell-adrenal cell superfusion. Endocrinology 100: 1153-1159

11. Mallampati RS, Johnson DC (1973) Serum and pituitary prolactin, $\mathrm{LH}$, and FSH in androgenized female and normal rats treated with various doses of estradiol benzoate. Neuroendocrinology 11 : $46-56$

12. Nett TM, Adams TE (1978) Further studies on the radioimmunoassay of gonadotrophin releasing hormone: effect of radioiodination, antiserum and unextracted serum on levels of immunoreactivity in serum. Endocrinology 101: 1135-1144 
13. Cheng HC, Johnson DC (1974) Temporal changes in serum estradiol and prolactin in immature female rats given a single injection of estradiol benzoate. Steroids 24: 657-664

14. Exley D, Johnson MW, Dean PDG (1971) Antisera highly specific for $17 \beta$-estradiol. Steroids 18: 605-615

15. Campbell CS, Schwartz NB, Firlet MG (1977) The role of the adrenal and ovarian steroids in the control of serum LH and FSH. Endocrinology 101: 162-172

16. Brown-Grant K, Greig F (1975) A comparison of changes in the peripheral plasma concentrations of luteinizing hormone and follicle stimulating hormone in the rat. J Endocrinol 65:389

17. Tapper CM, Naftolin F, Brown-Grant K (1972) Influence of the reproductive state at the time of operation on the early response to ovariectomy in the rat. J Endocrinol 53:47-58

18. L'Age M, Langhoz J, Fechner W, Salzmann H (1974) Disturbances of the hypothalamo-hypophysial adrenocortical system in the alloxan diabetic rat. Endocrinology 95: 760-765

19. De Nicola AF, Fridman O, Del Castillo EJ, Folgia VG (1977) Abnormal regulation of adrenal function in rats with streptozotocin diabetes. Horm Metab Res 9: 469-479

20. Baldwin DM (1979) The effect of glucocorticoids on estrogen-dependent luteinizing hormone in ovariectomized rats and on gona- dotrophin secretion in the intact female rat. Endocrinology 105: $120-128$

21. Dudley SD, Ramirez I, Wade GN (1981) Deficits in the pituitary and brain cell nuclear retention of $\left({ }^{3} \mathrm{H}\right)$-estradiol in diabetic rats deprived of insulin: time course and metabolic correlates. Neuroendocrinology 33:1-9

22. Ahdieh HB, Hamilton JM, Wade GN (1983) Copulatory behavior and hypothalamic estrogen and progestin receptors in chronically insulin-deficient female rats. Physiol Behavior 31: 219-223

23. Katzenellenbogen BS (1980) Dynamics of steroid hormone receptor action. Ann Rev Physiol 42: 17-59

Received: 27 April 1984

and in revised form: 30 October 1984

Dr. D. C. Johnson

Department of Gynecology and Obstetrics

University of Kansas Medical Center

Kansas City, KS 66103

USA 